\title{
Linking foraging behaviour of the northern elephant seal with oceanography and bathymetry at mesoscales
}

\author{
Samantha E. Simmons ${ }^{1, *}$, Daniel E. Crocker ${ }^{2}$, Raphael M. Kudela ${ }^{3}$, Daniel P. Costa ${ }^{1}$ \\ ${ }^{1}$ Department of Ecology and Evolutionary Biology, University of California Santa Cruz, Center for Ocean Health, \\ 100 Shaffer Road, Santa Cruz, California 95060-5730, USA \\ ${ }^{2}$ Department of Biology, Sonoma State University, Rohnert Park, California 94928, USA \\ ${ }^{3}$ Department of Ocean Sciences, University of California, Santa Cruz, California 95064, USA
}

\begin{abstract}
We examined the foraging behaviour of 12 adult female northern elephant seals in relation to mesoscale oceanographic features between 1995 and 1997. Females were divided into 3 groups based on the geographic region to which they migrated ('coastal', 'coastal-oceanic' and 'oceanic'). We defined focal foraging areas (FFAs) using satellite telemetry and average daily transit rates of $\leq 0.4 \mathrm{~m} \mathrm{~s}^{-1}$, and examined characteristics of FFAs with respect to sea surface temperature (SST), sea surface temperature gradient (SSTg), sea level anomaly (SLA) and bathymetry using logistic regression models. Shallow bathymetry was significant for the coastal grouping of females and we examined the prevalence of benthic dives using a dive index ratio (DI), calculated by dividing mean maximum dive depth $(\mathrm{m})$ by ocean depth $(\mathrm{m})$ at each location for all 12 females. An additional 6 adult males were included in this analysis to quantify and elucidate differences in benthic foraging mode between the sexes. DI comparisons revealed significantly greater prevalence of benthic diving in FFAs in males than females $\left(\chi^{2}=10.588, p<0.01\right)$. However, one coastal female did show a higher occurrence of benthic dives in FFAs than other females, and had significantly greater rates of mass gain. The importance of each oceanographic variable differed between the 3 groups of females. Overall, model results showed SST to be the most influential factor related to FFAs. Additionally, 6 females had FFAs that were characterised by greater SSTg and higher SLA. These characteristics are consistent with anti-cyclonic eddies that occur throughout the range of elephant seals. Semipermanent eddies, such as the Haida and Sitka eddies of the Alaska gyre, may be particularly important in determining FFAs for some female northern elephant seals.
\end{abstract}

KEY WORDS: Mirounga angustirostris $\cdot$ Temperature $\cdot$ Benthic $\cdot$ Mesoscale $\cdot$ Eddies $\cdot$ Sex

\section{INTRODUCTION}

Understanding habitat structure in the marine environment is vital to address questions about the foraging behaviour and success of pelagic predators and to begin to understand how these organisms may be affected by, or respond to, annual and long-term changes in ocean climate. Our ability to monitor and understand how resources are distributed in the ocean and how organisms find and exploit those resources has increased with technological advances in the last
20 yr (Olson \& Backus 1985, Costa 1993). We now have the ability to track the movements and behaviour of top predators at the same scale that oceanographers are able to characterise the oceanographic environment (Block et al. 2002). Remotely sensed satellite data of oceanographic characteristics, such as sea surface temperature (SST) and sea level anomaly (SLA) allow a synoptic overview of changing features of large areas and have been used to examine changes in hydrographic properties (Moron et al. 1998, Strub \& James 2002, Sumner et al. 2003). 
Satellite tracking data from marine predators such as turtles, tuna and seals have been examined in relation to remotely sensed oceanographic features (Polovina et al. 2000, 2001, Block et al. 2002, Ream et al. 2005, Campagna et al. 2006).

The behaviour of top marine predators may be influenced by a variety of multi-scale environmental features such as bathymetry, current systems, fronts and eddies. In neritic habitats, shallow bathymetry influences water column structure (Pickard \& Emery 1990, Xie et al. 2002) and also provides a physical substratum (sea floor) for organisms to exploit. The proximity of the substratum to the surface allows air-breathing vertebrates to forage in the benthic environment. In pelagic habitats, deep bathymetric features such as seamounts and oceanic ridges influence the hydrography (Roden 1986), but are largely beyond the reach of air-breathing vertebrates as a physical substratum on which to forage.

In the pelagic environment, structures such as fronts, eddies and jets may define foraging patches useful to predators because they aggregate nutrients and planktonic organisms, promoting increased productivity and influencing several trophic levels in pelagic food webs (Olson et al. 1994, Whitney \& Robert 2002). A front is defined simply as an area of rapid change in a physical variable, such as temperature, over a small spatial distance, horizontal or vertical (Olson et al. 1994). Remotely sensed satellite data have been used to identify SST and chlorophyll fronts (Polovina et al. 2001). Close associations with fronts have been found for turtles, albatross and southern elephant seals (Boyd \& Arnbom 1991, Polovina et al. 2000, Field et al. 2001, Hyrenbach et al. 2002). These studies are beginning to identify the habitat features or patches that are important to top marine predators.

One wide-ranging top predator in the North Pacific is the sexually dimorphic northern elephant seal Mirounga angustirostris. This species exhibits distinct terrestrial and aquatic phases, with all energy required for the expensive processes of breeding and moulting on land derived from biannual foraging trips (Costa et al. 1986). Site fidelity, relative ease of handling (compared with some birds, tuna and cetaceans) and established proxies for foraging behaviour at sea, such as slow transit rate and characterisation of foraging type dives (Le Boeuf et al. 1988, 2000a, Crocker et al. 1997, Kuhn 2006, Hassrick et al. 2007), provide a unique opportunity to examine the foraging behaviour of this top predator in relation to oceanography.

Adult female northern elephant seals spend about 2 mo at sea between breeding and moulting, and then up to $8 \mathrm{mo}$ at sea following the moult. Adult females generally travel due west from the rookery and forage over water thousands of meters deep in the North
Pacific. From dive shape and location, females have been hypothesized to forage meso-pelagically in the open ocean (Le Boeuf et al. 1989, 1992, Naito et al. 1989, Crocker et al. 1997). Females instrumented in successive years, or on successive trips, show more variability in foraging locations than males, which focus on coastal areas (Le Boeuf et al. 2000a). The same pattern of sexual segregation during foraging migrations has also been recorded in southern elephant seals Mirounga leonina, with males remaining over the shelf and most females foraging off the shelf or over deep pelagic waters (Hindell et al. 1991a). This sexual segregation during the period of resource acquisition is of particular interest in elephant seals, given their extreme sexual size dimorphism, with northern elephant seal males being up to 3 or 4 times larger than females (Deutsch et al. 1994).

Few studies have explicitly addressed how the at-sea behaviour of northern elephant seals is shaped by the oceanographic environment (Hakoyama et al. 1994, Crocker et al. 2006). In contrast, the behaviour of southern elephant seals has been examined quantitatively in relation to bathymetry (McConnell et al. 1992, Bradshaw et al. 2004) and satellite derived surface features such as SST, SLA, sea surface temperature gradients (SSTg), ocean colour, sea ice concentration, frontal zones and mesoscale eddies (Bradshaw et al. 2004, Campagna et al. 2006), as well as water column properties such as temperature (Boyd \& Arnbom 1991, Hindell et al. 1991a, Field et al. 2001).

Unlike southern elephant seals, which have been shown to dive in direct association with the thermocline (Boyd \& Arnbom 1991) and change their behaviour when moving between water masses (Field et al. 2001), no such associations have been found for northern elephant seals. Rather it has been concluded that their habitat does not provide abrupt thermal changes for elephant seals to exploit (Hakoyama et al. 1994). While foraging proxies in both species have been positively associated with colder SSTs (Bradshaw et al. 2004, Crocker et al. 2006), Crocker et al. (2006) also found that El Niño events had a significant effect on the foraging success of females, as measured by mass gain while at sea. However, success varied greatly in El Niño years, and females that were most successful had high rates of mass gain and used foraging areas with colder SSTs that were more similar to those of non-El Niño years.

Studies on southern elephant seals in relation to oceanographic features have management implications for some declining sub-populations, often finding overlaps with commercial fisheries (Hindell et al. 2003, Field et al. 2004). Little is known of the environmental or fisheries interactions in northern elephant seals. Given the lack of information on north- 
ern elephant seals in relation to their environment and the effects of the changing ocean environment on them (Le Boeuf \& Crocker 2005, Crocker et al. 2006), we considered the pelagic foraging behaviour of females in relation to bathymetry and 3 oceanographic variables (SST, SSTg, SLA). We used satellite telemetry data from 12 adult females and calculated an average daily transit speed to define foraging areas. We then examined which variables characterised areas important to foraging females and how this varied depending on the geographic region to which they migrated.

Additionally we found a subset of females that foraged in locations similar to those of adult males. This was interesting, given the extreme sexual dimorphism in this species and the previously described differences between males and females (Hindell et al. 1991a,b, Le Boeuf et al. 2000a). To further examine and quantify these differences we derived a ratio of dive depth to ocean depth that was used to describe the proportion of dives in close proximity to the ocean floor. We then compared the occurrence of these benthic dives between males and females both within and outside foraging areas.

\section{MATERIALS AND METHODS}

Deployments. The at-sea behaviour of 12 adult female and 6 adult male northern elephant seals was determined during 18 foraging trips originating from Año Nuevo, California, USA, in 1995 (7 trips), 1996 (9 trips) and 1997 (2 trips), during both post-breeding or spring (8 trips) and post-moult or fall migrations (10 trips).

Deployment methods are described in Le Boeuf et al. (2000a). In brief, the seals were immobilized with a teletamine $\mathrm{HCl} /$ zolazepam $\mathrm{HCl}$ injection administered intramuscularly (Baker et al. 1990). This was followed with intravenous injections of ketamine $\mathrm{HCl}$ as necessary to maintain immobilization (Briggs et al. 1975). While seals were immobilized, $0.5 \mathrm{~W}$ satellite platform transmitter terminals (PTTs) were attached to the top of the heads with epoxy adhesive (Fedak et al. 1983). Diving records were obtained using time-depth recorders (TDRs). Fifteen of the TDRs were Mk3e GLTDRs (Wildlife Computers) and two were Datagrabbers (Fletcher et al. 1996). Dive recorders were attached as described above to the dorsal pelage on the midline above the shoulders. When the seals returned to the rookery, the instruments were removed and the epoxy mounts were shed during the annual moult.

Data handling. Satellite data: The Argos satellite system (Service Argos) was used to determine at-sea location. The PTTs were programmed to transmit every $34 \mathrm{~s}$ while the seal was at the surface, as determined by a salt-water switch. Elephant seals dive continuously while at sea, generally spending about 2 to $3 \mathrm{~min}$ at the surface between dives (Le Boeuf et al. 1988, 2000b). Satellite tracks for all animals were filtered using a $3.5 \mathrm{~m} \mathrm{~s}^{-1}$ maximum transit speed to remove erroneous locations (McConnell et al. 1992, Le Boeuf et al. 2000a). Females were divided into 3 groups (oceanic, coastal-oceanic and coastal) based on the geographic extent of their tracks, following criteria similar to those of Hakoyama et al. (1994).

Defining focal foraging areas (FFAs): Daily transit speed was calculated from the speed-filtered tracks using the highest quality location (as provided by ARGOS) from each day and was based on the great circle distance between those locations and elapsed time (Le Boeuf et al. 2000a, Crocker et al. 2006). This approach resulted in $99 \%$ of locations being temporally separated by $>6 \mathrm{~h}$, thus minimizing the effect of ARGOS error on determination of transit speed. Daily transit speed was then averaged over $2 \mathrm{~d}$ and used to divide the behaviour of seals into 2 states. FFAs were defined by average daily transit speeds of $\leq 0.4 \mathrm{~m} \mathrm{~s}^{-1}$ $\left(1.44 \mathrm{~km} \mathrm{~h}^{-1}\right)$. Transit speeds $>0.4 \mathrm{~m} \mathrm{~s}^{-1}$ were considered representative of areas of mixed foraging and transit behaviour (MFTs). The threshold of $0.4 \mathrm{~m} \mathrm{~s}^{-1}$ was chosen as it is the daily transit rate that would occur due to average error in ARGOS location alone (35.5 km d ${ }^{-1}$, Le Boeuf et al. 2000a). Or, in other words, a seal that remained in one location for $24 \mathrm{~h}$ could appear to have a transit rate of $0.4 \mathrm{~m} \mathrm{~s}^{-1}$ due to the error in ARGOS locations alone. Positive correlations between mass gain at sea and percentage time spent in FFAs, increases in the proportion of foraging type dives in FFAs (Le Boeuf et al. 2000a) and increases in prey capture events with decreasing transit speed (Kuhn 2006) all support the use of transit speed alone to divide behaviour at sea.

Oceanographic variables: For each female, values for SST, SSTg and SLA were extracted at each location using custom software (Big Seal Tool Kit 1.3.3). The software used SST data from the NASA Physical Oceanography Distributed Active Archive Center (PO.DAAC) at the Jet Propulsion Laboratory, California Institute of Technology. A full description of data processing and quality is available at: http://podaac. jpl.nasa.gov/products/product016.html. Data were weekly averages of Advanced Very High Resolution Radiometer (AVHRR)-derived SST with $18 \mathrm{~km}$ spatial resolution. SSTg for each location were also obtained using Big Seal Tool Kit 1.3.3 by computing a spatial grid containing the magnitude of the SSTg for each $8 \mathrm{~d}$ dataset and then matching this with the track of each female by time. A bicubic interpolation was used to 
derive the SSTg value for a particular point along the track from adjacent grid cells. Gradients represented temperature change in ${ }^{\circ} \mathrm{C}$ per degree latitude/longitude surrounding each location.

Values of SLA for each location were from the World Ocean Circulation Experiment (WOCE) TOPEX/ POSEIDON altimetry data, and were also obtained from NASA PO.DAAC at the Jet Propulsion Laboratory, California Institute of Technology. Data were $5 \mathrm{~d}$ averages of SLA interpolated over $1.0^{\circ}$ in latitude and longitude. Anomalies were derived relative to a geoid generated from a 4 yr average (1993-1996) of sea surface height. A full description of data quality and processing is available at: http://podaac. jpl.nasa.gov/ products/product172.html.

Additionally for each location, a value of ocean depth was derived from the dataset (ca. $131 \mathrm{MB}$ ) available at ftp://topex.ucsd.edu/pub/global_topo_2min/ topo_8.2.img (with a $4 \mathrm{~km}$ horizontal resolution). Seafloor depths were interpolated for each location from the gridded topex data.

We did not explicitly address the question of an appropriate spatial scale for examination of the tracking data with remotely sensed oceanography, as has been advocated in other studies (Guinet et al. 2001, Bradshaw et al. 2002). However, the temporal and spatial scales of datasets used $(\mathrm{SSTg}=$ weekly, $18 \mathrm{~km}$; SLA $=5 \mathrm{~d}, 1.0^{\circ}$; behaviour $=2 \mathrm{~d}$ ), oceanographic features considered (mesoscale features $\sim 100 \mathrm{~s} \mathrm{~km}$ ) and average error in animal positions (Le Boeuf et al. 2000a, Vincent et al. 2002) were comparable and thus appropriate.

TDR data: Location and TDR data were synchronized by time. For each location, average maximum dive depth $( \pm \mathrm{SE})$ was obtained using the dive before and the dive after the location. This averaging was necessary in order to compare dive depth with bathymetry, as the bathymetry was determined by seal location at the surface. A 2-dive average was used as seals can travel considerable horizontal distances $(1.2 \mathrm{~km})$ in a single dive (Le Boeuf et al. 1992), and PTT locations were not obtained for each surfacing. The resulting measure, referred to hereafter as dive depth, is the 2-dive average of maximum dive depth associated with each filtered location recorded for each seal.

To quantify diving behaviour and address the relative importance of bathymetry to males and females, a dive index ratio (DI) was calculated by dividing dive depth by ocean depth to generate a single variable. A DI value of 1.0 indicated dives to the ocean floor, i.e. benthic diving (Thompson et al. 1998). The DI allowed comparison between males and females on the same relative scale, regardless of geographic location. Further, dives with a high DI ratio were verified as being benthic by examining the absolute difference between dive depth and ocean depth.

Analyses. All statistical analyses were performed using Systat 10.0 (SPSS) or JMP 4.0 (SAS Institute). In order to determine which of the oceanographic variables were important for the at-sea behaviour of females, the means for all variables when in FFAs were compared with those when in MFT areas, for each individual. Trends in these data are reported and were quantified using logistic regression models.

For all regressions and modelling, the dataset was first considered as a whole and then considered when split by geographic group. Oceanographic variables were included in models if logistic regression of that variable (independent factor) against foraging state (FFA or MFT, dependent factor) indicated it was a significant predictor of foraging state. Replicate locations for each individual were nested within 'individual' in the models and all significant variables were then run in logistic models using a backwards stepwise approach to eliminate non-significant effect terms, based on likelihood ratio tests, and to reach the final reduced model.

None of the variables were normally distributed, nor did transformations significantly improve the normality of the data. Therefore, testing for differences between male and female DIs was done using a Kruskal-Wallis test (SYSTAT 10.0).

\section{RESULTS}

\section{Locations at sea}

Coastal females travelled north of $50^{\circ} \mathrm{N}$ to Alaska and into the coastal zone off the Aleutian island chain (Fig. 1a, seals Deb and Mag, Table 1). Coastal-oceanic females departed from Año Nuevo in a more northerly direction and spent the majority of their time at sea in the Gulf of Alaska or off the Washington coast (Fig. 1b, seals Gre, Nil, Mar and Yet2, Table 1). Finally, oceanic females made a west-north-west departure from Año Nuevo and continued in an offshore loop (Fig. 1c, seals Jaz, Kar, Lis, Pat, Pel and Yeti; Table 1). From the 12 female tracks, 3005 locations were received and associated dive data were recorded for 2278 of the locations.

For 2 females (seals Kar and Deb, Table 1), TDR failures early in their migrations meant that they were omitted from the comparison with males. Thus, for the male/female comparison there were 10 females and 6 males. However, as we had full satellite tracks for seals Kar and Deb, they were included in the analysis of female foraging in relation to oceanography ( $\mathrm{N}=12$ females $)$. 

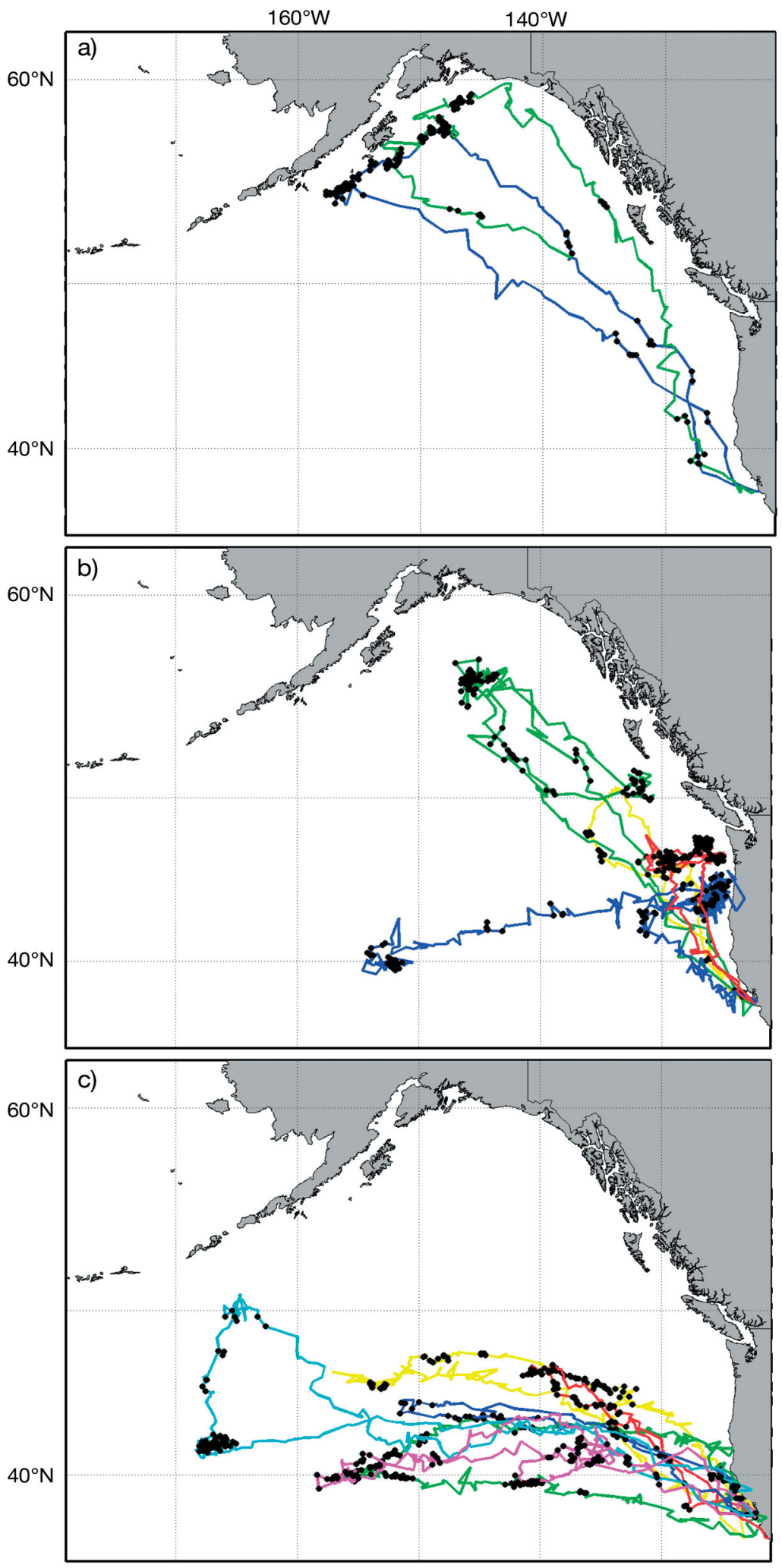

Fig. 1. Mirounga angustirostris. Tracks for all 12 females showing locations within focal foraging areas (FFAs) $(\bullet$ ) divided by oceanographic region (see Table 1). (a) Coastal females $(\mathrm{n}=2)$, (b) coastal-oceanic females $(\mathrm{n}=4)$ and (c) oceanic females $(n=6)$. The track of each female is represented by a different colour

\section{FFAs in relation to oceanography}

Some general patterns were evident when considering mean values for oceanographic variables between FFAs and MFTs. These general trends included 10 out of 12 females with colder SST when in FFAs versus MFT areas, 7 out of 12 females with greater SSTg when in FFAs and 8 out of 12 females with higher SLA when in FFAs versus MFT areas (Fig. 2). Overall, FFAs of 6 females were characterised by greater SSTg and higher SLA, on average, than MFT areas.

Due to the differences in oceanography between spring and fall (Fig. 2), season was always included as a variable in the full model. However, season was never a significant effect term and was always eliminated from the final reduced models (Table 2).

When all females were considered as a single group, all of the variables in the final model were significant predictors of FFAs, including SST, SLA and their interaction (Table 2). However, other than individual effects, SST was the most influential $\left(\chi^{2}=35.15, p<0.01\right)$. When females were separated based on the geographic region of their tracks, ocean depth (OD) followed by SST were the most significant predictors of foraging state for oceanic and coastal females (Table 2). In contrast, for coastaloceanic females, SSTg and SLA were the most important variables (Table 2).

\section{Importance of bathymetry}

Male foraging behaviour was limited to a single FFA associated with locations on or near the continental shelf of the Aleutian island chain or off the Oregon coast (Fig. 3). Time spent in FFAs by females was shorter in duration and there were multiple FFAs in each trip (Figs. 1 \& 4). This was even true for the 2 coastal females Mag and Deb (Table 1), who spent a mean $( \pm \mathrm{SD})$ of $3.37 \mathrm{~d}( \pm 2.01)$ and $4.38 \mathrm{~d}( \pm 5.32)$ in FFAs, respectively.

For all 6 males, DI was significantly larger in FFAs than in MFT areas (Table 1). There was a significant difference in DI for 4 females, but with the reverse pattern to males, i.e. a smaller DI in FFAs versus 
Table 1. Mirounga angustirostris. Seal identification name, sex, deployment date, oceanographic grouping for females, and mean $( \pm \mathrm{SD})$ dive index ratio (DI: dive depth by ocean depth) for males and females in FFAs (focal foraging areas), MFTs (areas of mixed foraging and transit behaviour) and overall. O: oceanic; C: coastal; CO: coastal-oceanic group of females; S: spring; M: male; F: female (column 2) or fall (column 3)

\begin{tabular}{|c|c|c|c|c|c|c|}
\hline \multirow{2}{*}{ Seal } & \multirow{2}{*}{ Sex } & \multirow{2}{*}{$\begin{array}{l}\text { Deploy season } \\
\text { and year }\end{array}$} & \multirow{2}{*}{$\begin{array}{l}\text { Oceanographic } \\
\text { grouping }\end{array}$} & \multirow{2}{*}{$\mathrm{FFA}^{\mathrm{c}}$} & \multirow{2}{*}{$\begin{array}{l}\mathrm{DI}- \\
\mathrm{MFT}\end{array}$} & \multirow[b]{2}{*}{ Overall $^{c}$} \\
\hline & & & & & & \\
\hline $\operatorname{Kar}^{\mathrm{a}}$ & $\mathrm{F}$ & S 95 & $\mathrm{O}$ & - & - & - \\
\hline Yeti $^{\mathrm{b}}$ & $\mathrm{F}$ & S 95 & $\mathrm{O}$ & $0.072(0.035)$ & $0.100(0.067)$ & $0.087(0.056)$ \\
\hline $\mathrm{Pel}^{\mathrm{b}}$ & $\mathrm{F}$ & S 96 & $\mathrm{O}$ & $0.135(0.029)$ & $0.174(0.156)$ & $0.157(0.118)$ \\
\hline Jaz & $\mathrm{F}$ & S 96 & $\mathrm{O}$ & $0.131(0.031)$ & $0.130(0.059)$ & $0.130(0.052)$ \\
\hline $\mathrm{Deb}^{\mathrm{a}}$ & $\mathrm{F}$ & S 96 & $\mathrm{C}$ & - & - & - \\
\hline Nils $^{\mathrm{b}}$ & $\mathrm{F}$ & S 96 & $\mathrm{CO}$ & $0.168(0.066)$ & $0.204(0.160)$ & $0.197(0.147)$ \\
\hline Gre & $\mathrm{F}$ & F 95 & $\mathrm{CO}$ & $0.132(0.095)$ & $0.146(0.110)$ & $0.140(0.104)$ \\
\hline Yet2 & $\mathrm{F}$ & F 95 & $\mathrm{CO}$ & 0.156 (0.169) & $0.127(0.133)$ & $0.134(0.143)$ \\
\hline $\operatorname{Lis}^{\mathrm{b}}$ & $\mathrm{F}$ & F 96 & $\mathrm{O}$ & $0.078(0.026)$ & $0.083(0.031)$ & $0.082(0.030)$ \\
\hline Mag & $\mathrm{F}$ & F 96 & $\mathrm{C}$ & $0.237(0.200)$ & $0.305(0.310)$ & $0.277(0.271)$ \\
\hline Mar & $\mathrm{F}$ & F 96 & $\mathrm{CO}$ & $0.174(0.084)$ & $0.210(0.155)$ & $0.195(0.132)$ \\
\hline Pat & $\mathrm{F}$ & F 96 & $\mathrm{O}$ & $0.112(0.036)$ & $0.114(0.038)$ & $0.114(0.038)$ \\
\hline $\mathrm{Alt}^{\mathrm{b}}$ & M & F 95 & - & $0.631(0.356)$ & $0.304(0.384)$ & $0.516(0.394)$ \\
\hline $\mathrm{Pol}^{\mathrm{b}}$ & M & F 95 & - & $0.309(0.229)$ & $0.166(0.248)$ & $0.203(0.250)$ \\
\hline $\mathrm{Sam}^{\mathrm{b}}$ & M & F 95 & - & $0.760(0.265)$ & $0.224(0.314)$ & $0.461(0.396)$ \\
\hline $\operatorname{Lux}^{\mathrm{b}}$ & M & F 96 & - & $0.384(0.355)$ & $0.098(0.039)$ & $0.219(0.271)$ \\
\hline Bop $^{b}$ & M & S 97 & - & $0.575(0.432)$ & $0.188(0.270)$ & $0.391(0.410)$ \\
\hline $\mathrm{Moo}^{\mathrm{b}}$ & M & S 97 & - & $0.801(0.264)$ & $0.147(0.149)$ & $0.467(0.391)$ \\
\hline
\end{tabular}

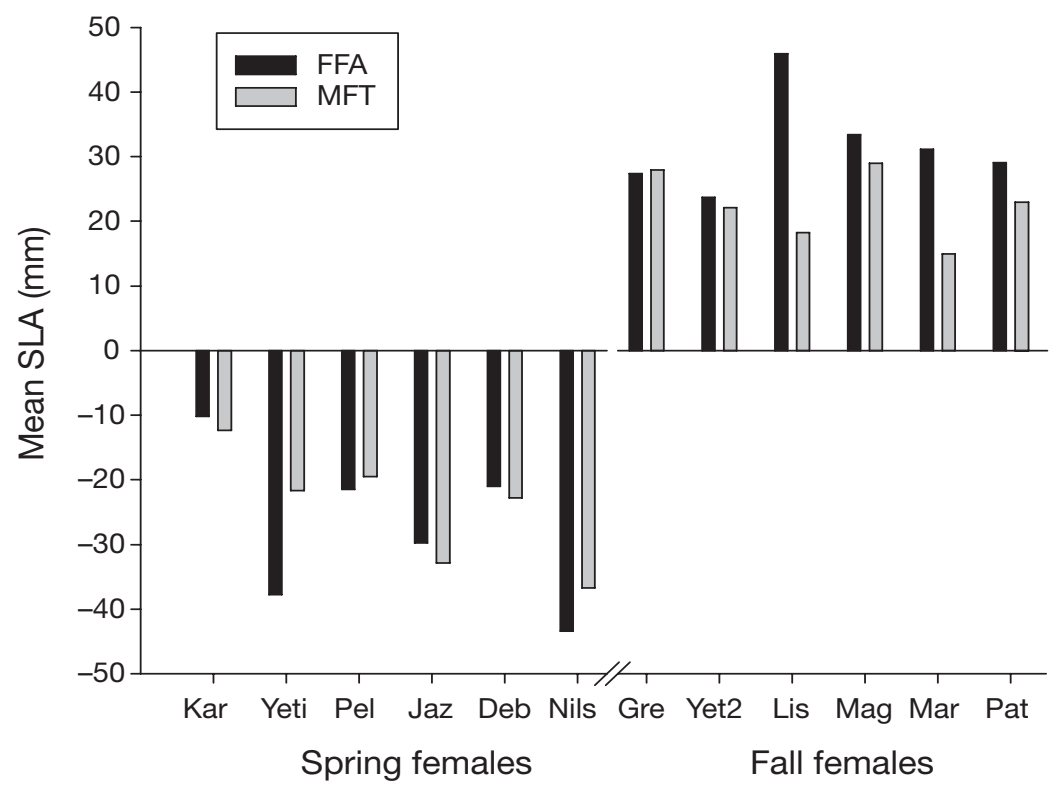

Fig. 2. Mirounga angustirostris. Mean sea level anomaly (SLA) for each female in focal foraging area (FFA) and areas of mixed foraging and transit behaviour (MFT). Negative and positive values of SLA reflect seasonal changes in the North Pacific

MFT areas. The mean DI of males was significantly larger than that of females in FFAs (Fig. 5, Table 1). However, in MFT areas there was no significant difference in mean DI between males and females (Fig. 5).

\section{DISCUSSION}

\section{FFAs in relation to oceanography}

Our results support the findings of Crocker et al. (2006) and Bradshaw et al. (2004), as the FFAs of 10 out of 12 females were associated with colder SST than other areas. This trend was supported by a significant logistic regression $\left(\chi^{2}=47.41, \mathrm{p}<0.0001\right)$ and a negative parameter estimate (Table 2), indicating that the probability of being in a FFA increased significantly with decreasing temperature. As SST was the most influential variable in the overall logistic model, we conclude that female elephant seals concentrate foraging effort in relatively colder areas, which is likely due to their prey favouring or being aggregated by colder waters (Condit \& Le Boeuf 1984, Olson \& Backus 1985, Strass 1992, Olson et al. 1994, Whitney \& Robert 2002).

The trends in mean values for oceanographic variables between FFAs and MFTs revealed that the FFAs of 6 females were characterised by greater SSTg and higher SLA, on average, than MFT areas. These properties 
match those of down-welling or anti-cyclonic eddies (Pickard \& Emery 1990). Thus, these structures are likely important foraging habitat for females. Mesoscale eddies have also been identified recently as important habitat features influencing the foraging migrations of juvenile southern elephant seals (Campagna et al. 2006).

Table 2. Logistic model results (parameter estimates, $\chi^{2}$ and p-value) for final, reduced models. Results are presented for all females together and for each of the geographic groupings. Parameter estimates were negative $(-)$, positive $(+)$ or undefined. SSTg: sea surface temperature gradient; SLA: sea level anomaly; OD: ocean depth; SEAL: individual females

\begin{tabular}{|c|c|c|c|c|}
\hline Model & df & $\begin{array}{l}\text { Parameter } \\
\text { estimate }\end{array}$ & $\begin{array}{l}\text { Likelihood } \\
\quad \text { ratio } \chi^{2}\end{array}$ & p-value \\
\hline \multicolumn{5}{|l|}{ All females } \\
\hline SST & 1 & - & 35.15 & $<0.01$ \\
\hline SLA & 1 & + & 24.60 & $<0.01$ \\
\hline $\mathrm{SST} \times \mathrm{SLA}$ & 1 & + & 18.54 & $<0.01$ \\
\hline SEAL & 11 & & 82.09 & $<0.01$ \\
\hline \multicolumn{5}{|c|}{ Oceanic females } \\
\hline OD & 1 & - & 70.05 & $<0.01$ \\
\hline SST & 1 & - & 14.20 & $<0.01$ \\
\hline $\mathrm{OD} \times \mathrm{SST}$ & 1 & - & 1.62 & 0.20 \\
\hline SEAL & 4 & & 14.10 & $<0.01$ \\
\hline \multicolumn{5}{|c|}{ Coastal-oceanic females } \\
\hline SST & 1 & - & 0.82 & 0.36 \\
\hline SSTg & 1 & + & 7.22 & $<0.01$ \\
\hline SLA & 1 & + & 15.44 & $<0.01$ \\
\hline SEAL & 3 & & 13.08 & $<0.01$ \\
\hline \multicolumn{5}{|c|}{ Coastal females } \\
\hline OD & 1 & + & 7.31 & $<0.01$ \\
\hline $\mathrm{SST}$ & 1 & - & 5.95 & 0.014 \\
\hline $\mathrm{OD} \times \mathrm{SST}$ & 1 & - & 15.47 & $<0.01$ \\
\hline SEAL & 1 & + & 4.38 & 0.036 \\
\hline
\end{tabular}

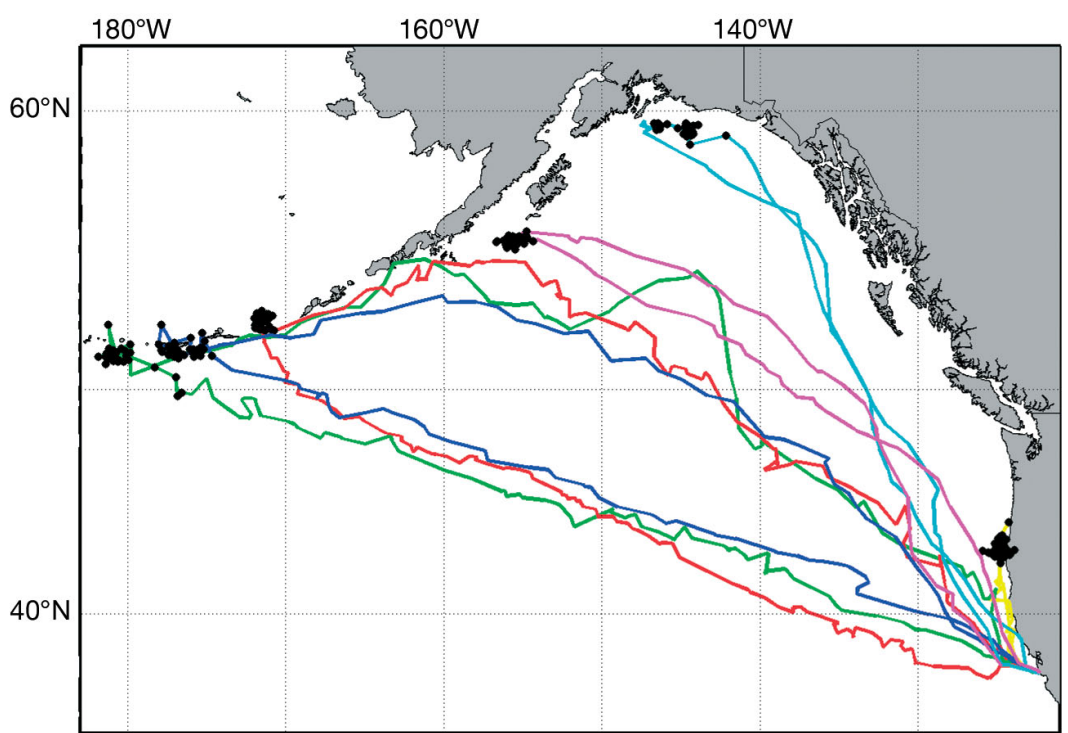

Fig. 3. Mirounga angustirostris. Tracks for 6 adult males (see Table 1). The track of each male is represented by a different colour. •: locations within FFAs

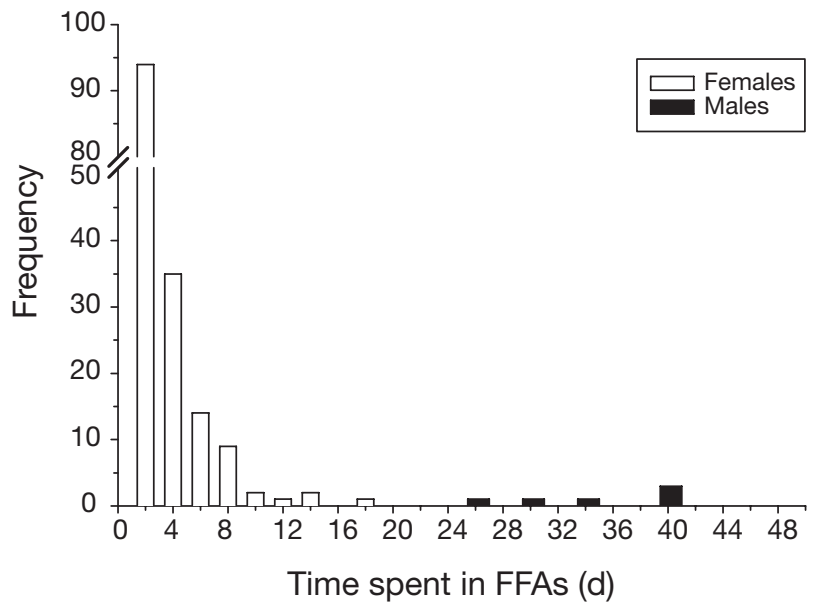

Fig. 4. Mirounga angustirostris. Time spent in FFAs for males and females. Seals Alt, Moo and Sam (see Table 1) spent 89, 55 and $41 \mathrm{~d}$, respectively, in FFAs and are all represented by the frequency of 3 for $>40 \mathrm{~d}$

Logistic modelling showed that all variables significantly influenced at-sea behaviour of females, but individual effects were the most significant. Instead of considering the behaviour of each female independently, we divided the data based on previously described geographic groupings (Hakoyama et al. 1994). These groupings seemed appropriate, given latitudinal differences in oceanographic variables such as SST and also the distinction of coastal females, for whom bathymetry might be a significant factor.

For both oceanic and coastal females, SST and ocean depth were significant predictors of FFAs. In contrast, SLA and SSTg were most highly associated with the FFAs of coastal-oceanic females. The foraging ranges of these females included the Gulf of Alaska gyre and the Alaska Current. Within this region, several mesoscale, often long-lived, anti-cyclonic eddies are generated (Tabata 1982, Musgrave et al. 1992, Crawford 2002). Eddies are formed along the coast in winter between 51 and $60^{\circ} \mathrm{N}$, and are often named after coastal cities near which they form, for example the 'Haida' and 'Sitka' eddies (Miller et al. 2005). They are about 200 to $300 \mathrm{~km}$ in diameter and propagate westward into the gyre, carrying relatively warm and fresh water away from the continental margin (Musgrave et al. 1992, Crawford 2002, 2005). The eddy core may be 1 or $2^{\circ} \mathrm{C}$ warmer than surrounding waters and characterised by a SLA of up to $0.4 \mathrm{~m}$ (Crawford 2002, Whitney \& Robert 2002). This large SLA and gradient in temperature across the mesoscale eddies may, at least in part, 


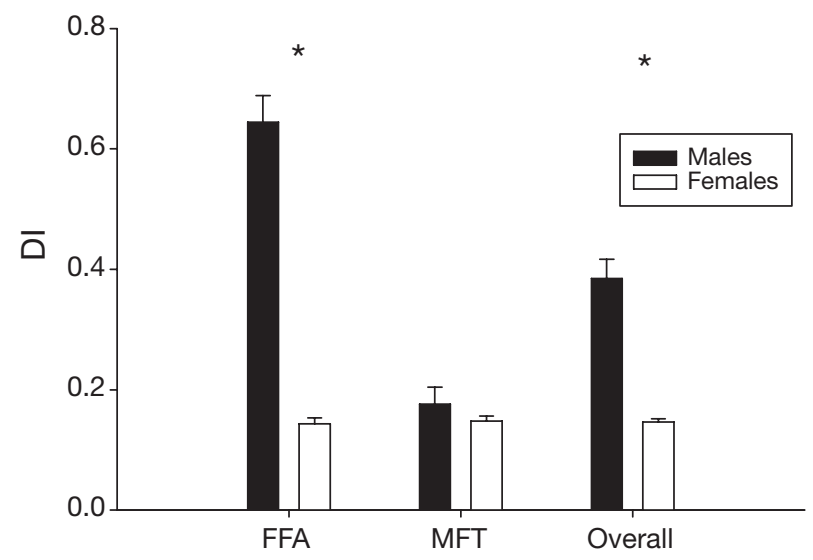

Fig. 5. Mirounga angustirostris. Mean $( \pm 2$ SE) dive index ratio (DI: dive depth by ocean depth) for males and females when in FFAs, MFTs and overall. *Significant differences between sexes $(\mathrm{p}<0.01$, Kruskall-Wallis)

explain the FFA results for coastal-oceanic females. In addition to physical effects, the eddies also affect the biology by concentrating nutrients and particulate organic carbon, and enhancing production (Whitney \& Robert 2002, Crawford et al. 2005). The formation and intensification of the eddies has also been shown to vary coincidentally with El Niño Southern Oscillation events (Okkonen et al. 2001) and may be involved in the great variability in foraging success seen in females in El Niño years (Crocker et al. 2006). Combining these factors provides a reasonable argument for the importance of such structures to foraging female elephant seals.

Mesoscale eddies are also generated in the subarctic frontal zone between 40 and $43^{\circ} \mathrm{N}$, which was frequented by the oceanic group of females. However, this low amplitude eddy field is much more variable over time in both intensity and stability, with surface heating often reducing horizontal temperature gradients (Roden 1991). We suggest that the intensity and longevity of the Alaska gyre eddies account for the importance of SLA and SSTg in the FFAs of coastaloceanic females. Further, we suggest that the latitudinal isotherms of the subarctic frontal zone, when considered at mesoscales, explain the importance of SST in the FFAs of oceanic females.

We considered surface features at temporal and spatial mesoscales, and while there is a connection between thermal structure on the surface and at depth, it is highly variable and cannot be accurately or consistently predicted (Pickard \& Emery 1990). One previous study did consider sub-surface temperature measures in relation to diving behaviour in northern elephant seals (Hakoyama et al. 1994). However, the instruments were recording temperature only every 5 or $10 \mathrm{~min}$. The data were then combined into daily averages of temperature for $20 \mathrm{~m}$ depth bins, and a strong thermocline was detected in the coastal region, but little thermal structure was detected in the pelagic environment. We suggest that this lack of thermal structure was due to insufficient sampling rates and coarse binning of the data (S. E. Simmons unpubl. data).

Juvenile southern elephant seals use frontal systems generated by bathymetry as well as mesoscale eddies (Campagna et al. 2006). In fact, one juvenile female was shown to dive differently within the structure of the eddy versus in other frontal zones (Campagna et al. 2006). The sub-surface structure of the water column and its relation to diving and foraging behaviour is an exciting area for future research, especially as some positive results have been obtained for diving behaviour in relation to thermocline depth in southern elephant seals (Boyd \& Arnbom 1991), Antarctic fur seals Arctocephalus gazella (Boyd et al. 2001), California sea lions Zalophus californianus (M. J. Weise unpubl. data) and king penguins Aptenodytes patagonicus (Charrassin \& Bost 2001), to name a few. Further investigation of diving behaviour in relation to subsurface features such as the thermocline is also necessary before we can understand the mechanistic reasons for changes seen in northern elephant seal foraging behaviour and success in El Niño years (Crocker et al. 2006).

\section{Importance of bathymetry}

Although ocean depth was a significant predictor of FFAs for both oceanic and coastal females, it is interesting to note that the parameter estimates for ocean depth have opposite signs for these 2 groups (Table 2). Thus, as might be expected, for oceanic females, foraging increased over deeper water, while for coastal females the reverse was true.

Closer, quantitative examination of the behaviour of coastal females in relation to other females and to males revealed 2 interesting patterns. First, despite travelling to areas that overlapped with 3 of the 6 males (Figs. 1a \& 3), both of the coastal females (seals Deb and Mag, Table 1) used multiple FFAs, unlike the single FFA per individual of all males studied. Second, there were no significant differences between the DIs of seal Mag when in FFAs versus other areas (Table 1); however, her DI in FFAs was the largest for all females and suggests that, although not as prevalent as in males, benthic foraging may be important in this female. Benthic foraging over the continental shelf and/or slope has been hypothesized to be beneficial to high rates of mass gain as it may offer relatively predictable and easily accessible resources versus the patchy and less predictable distribution of resources in 
pelagic areas (McConnell et al. 1992, Le Boeuf et al. 2000a). These ideas are interesting given that seal Mag's rate of mass gain was $2.30 \mathrm{~kg} \mathrm{~d}^{-1}$, almost 3 times the mean for other females $\left(0.96 \mathrm{~kg} \mathrm{~d}^{-1}\right)$ on their fall foraging migrations and much closer to the average rate of mass gain seen in males $\left(2.85 \mathrm{~kg} \mathrm{~d}^{-1}\right.$ ) (Le Boeuf et al. 2000a).

Although we were not able to calculate a DI for seal Deb, due to early TDR failure, this might have been revealing as her rate of mass gain was $0.73 \mathrm{~kg} \mathrm{~d}^{-1}$ (Le Boeuf et al. 2000a) and it would have been interesting to measure her DI in FFAs. By defining FFAs and deriving a quantitative measure of benthic diving behaviour, we have identified a useful tool for future comparisons among and between males and females. The DI results also quantitatively verify previous hypotheses about the benthic foraging mode of males versus the pelagic foraging mode of females (Crocker et al. 1997, Le Boeuf et al. 2000a). If differences in the rate of mass gain can be quantitatively related to mode of foraging using the DI, it will implicate benthic foraging as a driver of sexual searegation in this species.

\section{CONCLUSION}

We have shown that several oceanographic features or habitat structures may be important in defining FFAs of females and that these vary geographically. Although females show a lower degree of site fidelity between foraing locations on subsequent foraging migrations than males (Le Boeuf et al. 2000a), it would be interesting to re-examine their fidelity in light of the stability and productivity of mesoscale features in the different geographic regions, as has been considered for southern elephant seals (Bradshaw et al. 2004b). A female using the coastal zone might be expected to show the highest degree of site fidelity if indeed these resources are more stable through time. However, the fidelity of pelagic females may not be to a geographic location, but to long-lived, mesoscale eddies or other features that provide more predictably productive areas on an interannual time scale than previously recognised.

Identification of these features allows further consideration to be given to their subsurface structure and their influence on foraging behaviour. How these features vary during events that affect elephant seals on short time scales, such as El Niño events (Crawford 2005, Crocker et al. 2006) and understanding how longer term changes such as the Pacific Decadal Oscillation and global climate change functionally affect elephant seals remain to be elucidated and are an interesting area for future research.
Acknowledgements. We thank D. Houser, P. Webb, S. Blackwell, S. Hayes and J. Gedamke for their invaluable field assistance. M. Weise, L. Yeates, C. Kuhn, P. Robinson, S. Maxwell and 3 anonymous reviewers provided comments that greatly improved the manuscript. Original field work was funded in part by grants from the National Science Foundation (DCB8916967), the Office of Naval Research (ONR N00014-94-10455), Scripps Institution of Oceanography (ARPA MDA 97293-1-003, N00014-94-1-0692), and a gift from the G. E. Macgowan estate through the courtesy of G. Malloch. S.E.S. was supported by a grant from the Earl and Ethel Myers Foundation and a GSR from the Office of Naval Research. All research was conducted under NMFS permit 836 and animal handling procedures were approved by the Chancellor's Animal Research Committee UC Santa Cruz.

\section{LITERATURE CITED}

Baker JR, Fedak MA, Anderson SS, Arnbom T, Baker R (1990) Use of a tiletamine-zolazepam mixture to immobilize wild gray seals and southern elephant seals. Vet Rec 126:75-77

Block BA, Costa DP, Boehlert GW, Kochevar RE (2002) Revealing pelagic habitat use: the tagging of Pacific pelagics program. Oceanol Acta 25:255-266

Boyd IL, Arnbom T (1991) Diving behavior in relation to water temperature in the southern elephant seal-foraging implications. Polar Biol 11:259-266

Boyd IL, Hawker EJ, Brandon MA, Staniland IJ (2001) Measurement of ocean temperatures using instruments carried by Antarctic fur seals. J Mar Syst 27:277-288

Bradshaw CJA, Hindell MA, Michael KJ, Sumner MD (2002) The optimal spatial scale for the analysis of elephant seal foraging as determined by geo-location in relation to sea surface temperatures. ICES J Mar Sci 59:770-781

Bradshaw CJA, Higgins J, Michael KJ, Wotherspoon SJ, Hindell MA (2004a) At-sea distribution of female southern elephant seals relative to variation in ocean surface properties. ICES J Mar Sci 61:1014-1027

Bradshaw CJA, Hindell MA, Sumner MD, Michael KJ (2004b) Loyalty pays: potential life history consequences of fidelity to marine foraging regions by southern elephant seals. Anim Behav 68:1349-1360

Briggs GD, Henrickson RV, Leboeuf BJ (1975) Ketamine immobilization of northern elephant seals. J Am Vet Med Assoc 167:546-548

Campagna C, Piola AR, Rosa Marin M, Lewis M, Fernandez T (2006) Southern elephant seal trajectories, fronts and eddies in the Brazil/Malvinas confluence. Deep-Sea Res I 53:1907-1924

Charrassin JB, Bost CA (2001) Utilisation of the oceanic habitat by king penguins over the annual cycle. Mar Ecol Prog Ser 221:285-297

Condit R, Le Boeuf BJ (1984) Feeding-habits and feeding grounds of the northern elephant seal. J Mammal 65: 281-290

Costa DP (1993) The secret life of marine mammals: novel tools for studying their behavior and biology at sea. Oceanography 6:120-128

Costa DP, Le Boeuf BJ, Huntley AC, Ortiz CL (1986) The energetics of lactation in the northern elephant seal, Mirounga angustirostris. J Zool 209:21-33

Crawford WR (2002) Physical characteristics of Haida eddies. J Oceanogr 58:703-713

Crawford WR (2005) Heat and fresh water transport by eddies into the Gulf of Alaska. Deep-Sea Res II 52:893-908 
Crawford WR, Brickley PJ, Peterson TD, Thomas AC (2005) Impact of Haida eddies on chlorophyll distribution in the eastern Gulf of Alaska. Deep-Sea Res II 52:975-989

Crocker DE, Le Boeuf BJ, Costa DP (1997) Drift diving in female northern elephant seals: implications for food processing. Can J Zool 75:27-39

Crocker D, Costa DP, Le Boeuf BJ, Webb PM, Houser DS (2006) Impact of El Niño events on the foraging behavior of female northern elephant seals. Mar Ecol Prog Ser 309: $1-10$

Deutsch CJ, Crocker DE, Costa DP, Le Boeuf BJ (1994) Sex and age-related variation in reproductive effort of northern elephant seals. In: Le Boeuf BJ, Laws RM (eds) Elephant seals: population ecology, behavior and physiology. University of California Press, Berkeley, CA, p 169-210

Fedak MA, Anderson SS, Curry MG (1983) Attachment of a radio tag to the fur of seals. J Zool 200:298-300

Field I, Hindell M, Slip D, Michael K (2001) Foraging strategies of southern elephant seals (Mirounga leonina) in relation to frontal zones and water masses. Antarct Sci 13:371-379

Field IC, Bradshaw CJA, Burton HR, Hindell MA (2004) Seasonal use of oceanographic and fisheries management zones by juvenile southern elephant seals (Mirounga leonina) from Macquarie Island. Polar Biol 27:432-440

Fletcher S, Leboeuf BJ, Costa DP, Tyack PL, Blackwell SB (1996) Onboard acoustic recording from diving northern elephant seals. J Acoust Soc Am 100:2531-2539

Guinet C, Dubroca L, Lea Mary A, Goldsworthy S, Cherel Y, Duhamel G, Bonadonna F, Donnay JP (2001) Spatial distribution of foraging in female Antarctic fur seals Arctocephalus gazella in relation to oceanographic variables: a scale-dependent approach using geographic information systems. Mar Ecol Prog Ser 219:251-264

Hakoyama H, Le Boeuf BJ, Naito Y, Sakamoto W (1994) Diving behavior in relation to ambient water temperature in northern elephant seals. Can J Zool 72:643-651

Hassrick JL, Crocker DE, Zeno RL, Blackwell SB, Costa DP, Le Boeuf BJ (2007) Swimming speed and foraging strategies of northern elephant seals. Deep-Sea Res II 54: 369-383

Hindell MA, Burton HR, Slip DJ (1991a) Foraging areas of southern elephant seals Mirounga leonina as inferred from water temperature data. Aust J Mar Freshw Res 42: 115-128

Hindell MA, Slip DJ, Burton HR (1991b) The diving behavior of adult male and female southern elephant seals, Mirounga leonina (Pinnipedia, Phocidae). Aust J Zool 39: 595-619

Hindell MA, Bradshaw CJA, Sumner MD, Michael KJ, Burton HR (2003) Dispersal of female southern elephant seals and their prey consumption during the austral summer: relevance to management and oceanographic zones. J Appl Ecol 40:703-715

Hyrenbach KD, Fernandez P, Anderson DJ (2002) Oceanographic habitats of two sympatric North Pacific albatrosses during the breeding season. Mar Ecol Prog Ser 233: 283-301

Kuhn CE (2006) Measuring at sea feeding to understand the foraging behavior of pinnipeds. $\mathrm{PhD}$ thesis, University of California, Santa Cruz, CA

Le Boeuf B, Crocker D (2005) Ocean climate and seal condition. BMC (BioMed Central) Biol 3:9

Le Boeuf BJ, Costa DP, Huntley AC, Feldkamp SD (1988) Continuous, deep diving in female northern elephant seals, Mirounga angustirostris. Can J Zool 66:446-458

Le Boeuf BJ, Naito Y, Huntley AC, Asaga T (1989) Prolonged, continuous, deep diving by northern elephant seals. Can J Zool 67:2514-2519

Le Boeuf BJ, Naito Y, Asaga T, Crocker D, Costa DP (1992) Swim speed in a female northern elephant seal: metabolic and foraging implications. Can J Zool 70:786-794

Le Boeuf BJ, Crocker DE, Costa DP, Blackwell SB, Webb PM, Houser DS (2000a) Foraging ecology of northern elephant seals. Ecol Monogr 70:353-382

Le Boeuf BJ, Crocker DE, Grayson J, Gedamke J, Webb PM, Blackwell SB, Costa DP (2000b) Respiration and heart rate at the surface between dives in northern elephant seals. J Exp Biol 203:3265-3274

McConnell BJ, Chambers C, Fedak MA (1992) Foraging ecology of southern elephant seals in relation to the bathymetry and productivity of the Southern Ocean. Antarct Sci 4:393-398

Miller LA, Robert M, Crawford WR (2005) The large, westward-propagating Haida eddies of the Pacific eastern boundary. Deep-Sea Res II 52:845-851

Moron V, Vautard R, Ghil M (1998) Trends, interdecadal and interannual oscillations in global sea surface temperatures. Clim Dyn 14:545-569

Musgrave DL, Weingartner TJ, Royer TC (1992) Circulation and hydrography in the northwestern Gulf of Alaska. Deep-Sea Res A 39:1499-1519

Naito Y, Le Boeuf BJ, Asaga T, Huntley AC (1989) Long-term diving records of an adult Female northern elephant seal. Antarct Rec 33:1-9

Okkonen SR, Jacobs GA, Metzger EJ, Hurlburt HE, Shriver JF (2001) Mesoscale variability in the boundary currents of the Alaska Gyre. Cont Shelf Res 21:1219-1236

Olson DB, Backus RH (1985) The concentrating of organisms at fronts - a cold-water fish and a warm-core Gulf-Stream ring. J Mar Res 43:113-137

Olson DB, Hitchcock GL, Mariano AJ, Ashjian CJ, Peng G, Nero RW, Podesta GP (1994) Life on the edge: marine life and fronts. Oceanography 7:52-60

Pickard GL, Emery WJ (1990) Descriptive physical oceanography: an introduction. Butterworth Heinemann, Oxford

Polovina JJ, Kobayashi DR, Parker DM, Seki MP, Balazs GH (2000) Turtles on the edge: movement of loggerhead turtles (Caretta caretta) along oceanic fronts, spanning longline fishing grounds in the central North Pacific, 1997-1998. Fish Oceanogr 9:71-82

Polovina JJ, Howell E, Kobayashi DR, Seki MP (2001) The transition zone chlorophyll front, a dynamic global feature defining migration and forage habitat for marine resources. Prog Oceanogr 49:469-483

Ream RR, Sterling JT, Loughlin TR (2005) Oceanographic features related to northern fur seal migratory movements. Deep-Sea Res II 52:823-843

Roden GI (1986) Aspects of oceanic flow and thermohaline structure in the vicinity of seamounts. In: Uchida RN, Hyasi S, Boehlert GW (eds) Environment and resources of seamounts of the North Pacific. Proceedings of the workshop on environment and resources of seamounts in the North Pacific. US Department of Commerce. NOAA Tech Rep NMFS 43:3-12

Roden GI (1991) Subarctic-subtropical transition zone of the North Pacific: large-scale aspects and mesoscale structure. US Department of Commerce. NOAA Tech Rep NMFS 105:1-38

Strass VH (1992) Chlorophyll patchiness caused by mesoscale upwelling at fronts. Deep-Sea Res A 39:75-96

Strub PT, James C (2002) Altimeter-derived surface circulation in the large-scale NE Pacific gyres. Part 2: 1997-1998 El Niño anomalies. Prog Oceanogr 53:185-214 
Sumner MD, Michael KJ, Bradshaw CJA, Hindell MA (2003) Remote sensing of Southern Ocean sea surface temperature: implications for marine biophysical models. Remote Sens Environ 84:161-173

Tabata S (1982) The anticyclonic, baroclinic eddy off Sitka, Alaska, in the northeast Pacific Ocean. J Phys Oceanogr 12:1260-1282

Thompson D, Duck CD, McConnell BJ, Garrett J (1998) Foraging behaviour and diet of lactating female southern sea lions (Otaria flavescens) in the Falkland Islands. J Zool 246:135-146

Editorial responsibility: Rory Wilson (Contributing Editor), Swansea, UK
Vincent C, McConnell BJ, Ridoux V, Fedak MA (2002) Assessment of Argos location accuracy from satellite tags deployed on captive gray seals. Mar Mamm Sci 18: 156-166

Whitney F, Robert M (2002) Structure of Haida eddies and their transport of nutrient from coastal margins into the NE Pacific Ocean. J Oceanogr 58:715-723

Xie SP, Hafner J, Tanimoto Y, Liu WT, Tokinaga H, Xu HM (2002) Bathymetric effect on the winter sea surface temperature and climate of the Yellow and East China Seas. Geophys Res Lett 29:2228

Submitted: July 26, 2006; Accepted: April 17, 2007 Proofs received from author(s): September 10, 2007 